\title{
ATIVIDADES LÚDICAS DE MATEMÁTICA NO ENSINO FUNDAMENTAL
}

\section{LADICAL ACTIVITIES OF MATHEMATICS IN FUNDAMENTAL TEACHING}

\author{
Moisés dos Santos de Sales ${ }^{1}$; Carina Geovanna Nepomuceno Bezerra ${ }^{2}$; Johnny \\ Wostinson Alves Araujo ${ }^{3}$; Francisca da Rocha Barros Batista ${ }^{4}$; Antonio Evangelista Ferreira \\ Filho ${ }^{5}$.
}

\section{INTRODUÇÃO}

A matemática desde as series iniciais é concebida como uma matéria de difícil entendimento. Mais difícil ainda para os alunos é aplicá-la no dia a dia, devido às fórmulas abstratas e, muitas vezes desnecessária a esse fim. Um desafio que os professores de ensino fundamental enfrentam para elucidar o uso da matemática é chamar a atenção dos alunos para que sintam vontade em aprender e entender as fórmulas e como elas se aplicam no dia a dia. Apenas aplicar as fórmulas de modo mecânico e abstrato não estimula os alunos, especialmente, as crianças do ensino fundamental.

Diante disso, uma estratégia muito discutida atualmente para mudar essa realidade e fazer com que os alunos se sintam à vontade com a matemática e não mais ter a matéria como algo longe da realidade é a utilização das atividades lúdicas no processo ensino-aprendizagem. Dentre essas atividades, o uso de jogos no ensino da Matemática tem o objetivo de fazer com que os estudantes gostem de aprender essa disciplina, mudando a rotina da classe e despertando o interesse do estudante (MARINILZA, 2010). Utilizadas de forma bem elaborada e planejada, essas atividades podem despertar o interesse das crianças desde já para a matemática, ultrapassando a visão de que a matemática é apenas mecânica e abstrata.

Diante do exposto, o presente trabalho de abordagem qualitativa objetiva despertar o interesse do aluno pela matemática a partir dos primeiros anos da educação básica, para que, no decorrer de sua vida escolar, possa aumentar seu interesse por conceitos e ideias sobre a matemática.

Para tanto, utilizou-se um de um quebra cabeça em que as peças foram construídas em forma de figuras geométricas e usadas em uma imagem bem colorida de um desenho animado.

\section{RELATO DE EXPERIÊNCIA}

Para a maioria dos alunos, a Matemática é tida como uma disciplina de pouca participação no seu cotidiano e vista como algo de difícil compreensão, desinteressante e longe de ser uma maravilha, principalmente por apresentar diversas fórmulas abstratas que de fato não têm sentido algum antes de serem compreendidas pelo aluno (JUSSILENO \& JOSÉ, 2012). 
Nesse cenário, as atividades lúdicas mostram-se como ferramentas de melhoramento do processo Ensino-Aprendizagem também no âmbito da matemática, por tornar o conteúdo estudado mais atrativo, dinâmico e prazeroso para o aluno que se sentirá estimulado a entender tal conteúdo proposto pelo professor, o que possibilita ao professor um leque de alternativas nas demonstrações dos conteúdos trabalhados em sala de aula (JUSSILENO e JOSÉ, 2012).

Entre essas atividades lúdicas, os jogos matemáticos que explorem os conceitos geométricos, algébricos e aritméticos no Ensino Fundamental possibilitam aguçar a curiosidade e o interesse do aluno que muitas vezes considera esses assuntos desestimulante e fora da sua realidade (JUSSILENO e JOSÉ, 2012).

Entendendo a importância das atividades lúdicas no processo ensino-aprendizagem no ensino fundamental, desenvolveu-se um jogo no qual a ideia principal é de fácil compreensão para qualquer faixa etária. Trata-se de um quebra cabeça, mas com uma formação estrutural um pouco diferente das encontradas tradicionalmente. Utilizaram-se formas geométricas para confecção das peças, como quadrados, círculos, retângulos e triângulos (imagem 1). A imagem usada no quebra cabeça faz referência ao desenho Cyberchase, desenho animado estadunidensecanadense (imagem 2), em que três personagens, Jackie, Matheus e Inês, usam cálculos simples de matemática para resolver situações aparentemente difíceis, com o objetivo de vencer o vilão Hacker.

Esse trabalho foi apresentado na SEMAFIS (Semana da Matemática e Física) e promoveu uma aproximação mais voluntária por parte das crianças que se faziam presente, que se identificaram mais com os trabalhos que apresentavam uma imagem mais colorida. A princípio, o estranhamento com as formas geométricas do quebra cabeça foi nítido, mas com o decorrer da explicação sobre o jogo, as crianças se sentiram bem à vontade para manusearem as peças e se divertirem a cada vez que conseguiam montar a imagem.

No começo da atividade, foi necessário um acompanhamento por parte dos autores presentes, para orientar o encaixamento das peças e sobre o nome destas. Nessa interação no desafio de montar o quebra cabeça, percebeu-se que a noção das formas geométricas foi sendo incorporada aos poucos, uma vez que, ao pedir alguma peça ao colega, o mesmo já pronunciava a forma que a peça formava. 
Imagem 1: Fabricação das peças em formatos geométricos. Fonte: Própria

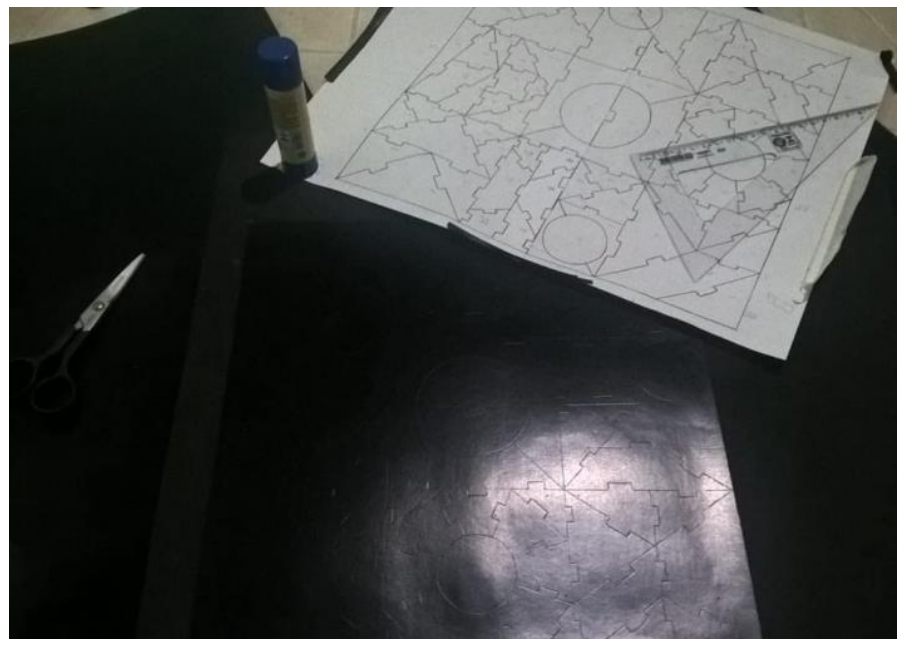

Imagem 2: Imagem utilizada no quebra cabeça. Fonte: Própria

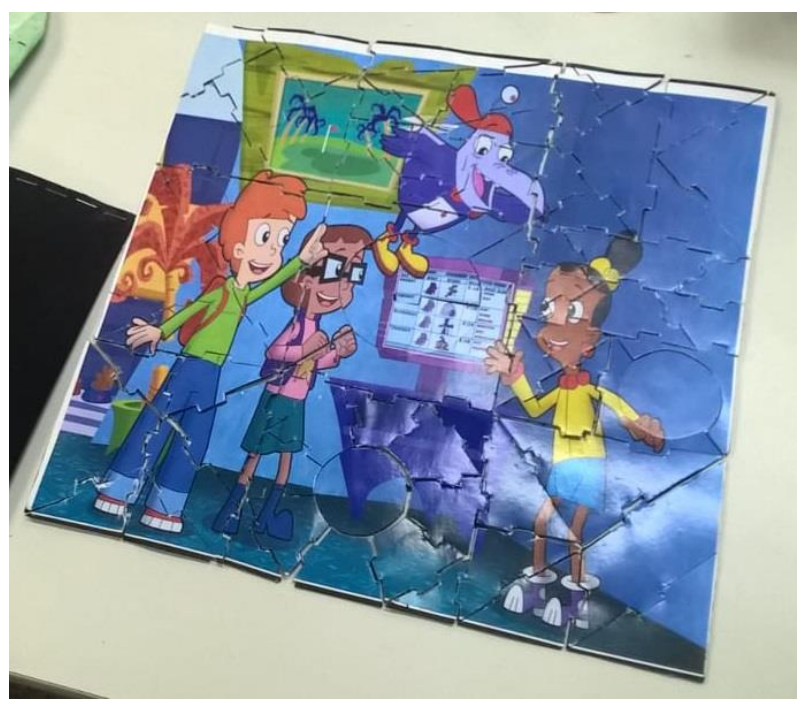

\section{CONSIDERAÇÕES}

Ao final da experiência, notou-se como atividades dessa natureza chamam a atenção das crianças, por se tratar de uma brincadeira bem conhecida por todos, e mais do que isso, o encaixe das peças diferentes, assim como o formato, instigou mais ainda as crianças a cumprirem o desafio, por se tratar de algo novo e que até então não conheciam.

Pode-se notar então que atividades lúdicas são um bom caminho para chamar atenção dos alunos das primeiras séries da educação básica, falando especialmente do ensino de matemática, no qual podem ser desenvolvidos os primeiros conceitos da matéria para que esta não seja mais vista pelos alunos como algo de difícil compreensão, e sim que está bem próxima do nosso dia a dia. Além disso, pode incentivar os alunos a se aprofundar mais nos conhecimentos matemáticos no decorrer da vida acadêmica.

Vale ressaltar que este é um trabalho inicial, por meio do qual buscou-se conhecer a 
importância dessas atividades no ensino da matemática para crianças, pretendendo-se aprofundá-lo com pesquisas com outras atividades dessa natureza.

\section{REFERÊNCIAS}

CUNHA, JUSSILENO. S.; SILVA, JOSÉ. A, V. A importância das atividades lúdicas no ensino da matemática. Natal, 2012.

SOUZA, MARINILZA. A importância das brincadeiras e jogos matemáticos na educação infantil. Aparecida de Goiania, Artigo de TCC - Faculdade Alfredo Nasser. 2010. 